\title{
Anti-inflammatory effects of salmeterol/fluticasone propionate 50/250 mcg combination therapy in Japanese patients with chronic obstructive pulmonary disease
}

\author{
This article was published in the following Dove Press journal: \\ International Journal of COPD \\ 17 April 2015 \\ Number of times this article has been viewed
}

\author{
Kazuhisa Asai' \\ Akihiro Kobayashi² \\ Yukio Makihara ${ }^{3}$ \\ Malcolm Johnson ${ }^{4}$ \\ 'Department of Respiratory Medicine, \\ Graduate School of Medicine, \\ Osaka City University, Osaka, Japan; \\ ${ }^{2}$ Biomedical Data Sciences, ${ }^{3}$ Medical \\ Affairs Respiratory Department, \\ GlaxoSmithKline, Tokyo, Japan; \\ ${ }^{4}$ Respiratory Global Franchise, \\ GlaxoSmithKline, Uxbridge, UK
}

Purpose: Using sputum neutrophils as the primary measure, and other inflammation biomarkers, this study evaluated the anti-inflammatory effects of the combination salmeterol $50 \mathrm{mcg}$ and fluticasone propionate $250 \mathrm{mcg}$ (SFC 250) in Japanese patients with chronic obstructive pulmonary disease (COPD).

Patients and methods: Patients were treated in a randomized, double-blind, parallel group, placebo-controlled trial with SFC 250 twice daily $(n=26)$ or placebo $(n=26)$ for 12 weeks. At the start and end of treatment, inflammation biomarkers (sputum and serum), lung function, and health status (COPD Assessment Test [CAT] questionnaire) were measured.

Results: Although a numerical decrease in differential neutrophil count was observed from baseline, SFC 250 did not significantly reduce sputum neutrophils compared with placebo, nor were there significant changes from baseline in the other biomarkers (sputum or serum), lung function, or CAT, versus placebo. Squamous epithelial cell contamination in some sputum samples rendered them unacceptable for analysis, which reduced the sample size to $n=19$ (SFC 250) and $\mathrm{n}=10$ (placebo). However, inclusion of contaminated samples did not affect the overall trend of the outcome. Ad hoc bootstrap statistical analysis showed a 27.9\% (SFC 250) and 1.3\% (placebo) decrease in sputum neutrophils. Sputum IL- 8 decreased by $43.2 \%$ after SFC 250 but increased by $48.3 \%$ with placebo. Responder analyses showed $42 \%$ of patients had $\geq 20 \%$ decrease in neutrophils from baseline; and $47 \%$ of patients had a $\geq 200 \mathrm{pg} / \mathrm{mL}$ change in sputum IL- 8 following SFC 250 versus 20\% after placebo; both changes are considered clinically relevant.

Conclusion: This study provides additional information about inflammation in Japanese COPD patients and is the first to study the anti-inflammatory effects of SFC 250 in this context and population. In the primary analysis, SFC 250 did not produce significant changes from baseline in sputum neutrophil levels or other sputum or serum inflammatory markers compared with placebo. Secondary ad hoc statistical analysis showed that SFC 250 reduced the number of sputum neutrophils and IL-8 compared with placebo.

Keywords: biomarkers, IL-8, neutrophils, serum, sputum

\section{Introduction}

Chronic obstructive pulmonary disease (COPD) is currently ranked as the tenth highest cause of death in Japan, and its prevalence is increasing. ${ }^{1}$ COPD is underrecognized in Japan, and data suggest its prevalence is also underestimated. ${ }^{2-5}$ COPD is considered a multicomponent disease, involving both pulmonary and systemic inflammation. ${ }^{1,6,7}$

In Japan, and globally, the current goals of COPD management include the improvement of symptoms and quality of life as well as the prevention and treatment
Correspondence: Yukio Makihara Medical Affairs Respiratory Department, GlaxoSmithKline, 6-I5 Sendagaya 4-chome, Shibuya-ku, Tokyo, I5I-8566 Japan

Tel +81357865336

Email yukio.2.makihara@gsk.com 
of exacerbations. ${ }^{1}$ Bronchodilators, such as long-acting beta-agonists (LABA) or long-acting muscarinic antagonists, used as monotherapy, do not always meet the COPD management goals, and patients often remain symptomatic. ${ }^{2}$ SFC, a combination of the LABA, salmeterol, and the inhaled corticosteroid fluticasone propionate (FP), provides greater relief of COPD symptoms and is more effective than salmeterol at reducing the exacerbation rate. ${ }^{8,9} \mathrm{SFC}$ is recommended for group C and group D patients. ${ }^{1,7}$ In Japan, Australia, and the United States, SFC 250, containing salmeterol $50 \mathrm{mcg}$ and FP $250 \mathrm{mcg}$, is approved for COPD. However, evidence of the anti-inflammatory effects of SFC in COPD has mainly come from studies using SFC 500 (salmeterol $50 \mathrm{mcg}$ and FP $500 \mathrm{mcg}$ ) in a Western population. ${ }^{10-12}$ Studies have been conducted with SFC 250 in COPD, ${ }^{8,13-16}$ but only one study with SFC 250 has been conducted in Japanese COPD patients, ${ }^{9}$ and none have measured anti-inflammatory effects.

Furthermore, spirometry, the recommended physiological measurement used in COPD diagnosis, does not provide information on underlying disease. ${ }^{17,18}$ However, measuring mediators of inflammation in COPD assesses pulmonary and systemic inflammatory processes, ${ }^{17}$ provides the potential for detecting early signals of efficacy, ${ }^{19}$ and generates information on whether inflammation is suppressed following pharmacological intervention. ${ }^{17-19}$ Neutrophils are the predominant cells in pulmonary inflammation, ${ }^{20}$ and their increased number in sputum is a characteristic of COPD. ${ }^{21}$

By measuring sputum and serum inflammation biomarkers, the anti-inflammatory effects of SFC 250 compared with placebo were evaluated in a Japanese COPD population. This is the first study to investigate the anti-inflammatory effects of SFC 250 in this context and population.

\section{Material and methods Subjects}

Japanese men and women, aged 40 to 80 years (inclusive), who were current or ex-smokers (pack history $\geq 10$ pack years), with a diagnosis of COPD, ${ }^{1,7}$ with postbronchodilator forced expiratory volume in 1 second $\left(\mathrm{FEV}_{1}\right) /$ forced vital capacity (FVC) ratio $<0.70$, and $\mathrm{FEV}_{1} \geq 40 \%$ and $<80 \%$ of predicted normal (15-60 minutes post-Saltanol ${ }^{\circledR}$ ) were eligible. Women were of nonchildbearing potential, ie, postmenopausal, surgically sterile, or of childbearing potential using protocol-specified contraceptive measures. Subjects were excluded if they had a diagnosis of bronchial asthma, chronic respiratory failure, or any respiratory disorder other than COPD; had undergone lung volume reduction, lung transplant, or had a chest X-ray (or computed tomography scan) indicating a diagnosis other than COPD within 6 months prior to screening; had a COPD exacerbation or respiratory infection requiring systemic corticosteroid, antimicrobial therapy, or hospitalization within 6 weeks prior to screening; or had significant abnormalities in electrocardiogram, vital signs, and clinical laboratory tests at screening.

Written informed consent was obtained prior to any study procedures. The study was conducted in accordance with the ethical principles of the Declaration of Helsinki and approved by the institutional review board (IRB) of the participating centers.

\section{Study design}

This was a randomized, double-blind, placebo-controlled, parallel group study (Clinicaltrials.gov identifier: NCT01607398) conducted between May 16, 2012 and July 10, 2013 at three sites in Japan. It comprised a screening visit scheduled 4 weeks prior to the first dose, which was administered at baseline. Treatment was administered twice daily for 12 weeks. Assessments were performed on the day of the first dose and 1 day after the last dose at week 12. Follow-up assessments were performed 1 week after the last dose. The first dose could be administered up to 5 weeks after the screening visit if no appropriate sputum sample was collected at baseline; if a sputum sample was not collected at the revisit, the subject was withdrawn from study. Subjects were randomized (1:1) to receive one inhalation, twice daily, of either SFC 250 or placebo, via a Diskus ${ }^{\circledR}$ inhaler (GlaxoSmithKline KK, Tokyo, Japan) for 12 weeks. Site staff randomized patients to treatment using the schedule generated by the validated GlaxoSmithKline Registration and Medication Ordering System. From study start to follow-up, only the short-acting anticholinergic drug oxitropium was allowed to be used alongside the study drug.

\section{Assessments}

\section{Efficacy}

Sample collection and assessments were performed twice during the study: at baseline and week 12. Induced sputum samples were obtained according to guidelines of the European Respiratory Society's Task Force, as previously described. ${ }^{22}$ Neutrophil and other inflammatory cell counts were measured using a cytological specimen of induced sputum, by May-Grunwald Giemsa staining, in Osaka City University laboratory. IFN-gamma-positive cells and perforin-positive cells in induced sputum were stained using the $\mathrm{ABC}$ method and diaminobenzidene, and assessed via microscopy. IL-8 (enzyme-linked immunosorbent assay 
[ELISA]), myeloperoxidase (ELISA), high-sensitivity C-reactive protein (hs-CRP) (latex-enhanced nephelometry), and surfactant protein (SP)-D (enzyme immunoassay [EIA]) levels were measured in induced sputum supernatant. IL-6 (ELISA), IL-8 (ELISA), hs-CRP (latex-enhanced nephelometry), SP-D (EIA), and Clara cell-16 (ELISA) levels were measured in serum. Inflammatory biomarkers, collected from sputum supernatant, were measured using standard immunochemical assays, by SRL Medisearch Inc. (Sagamihara, Japan). FEV ${ }_{1}$ and $\mathrm{FVC}$ were measured using a Chestgraph HI 105 spirometer (Chest MI Inc., Tokyo, Japan) at 30 minutes following the salbutamol administration. The highest of three technically acceptable values was recorded. The panel of inflammatory markers in sputum and serum was selected on the basis of a large-scale study, ECLIPSE ${ }^{23}$ and were used for independent purposes (ie, sputum was used as a biomarker for airway inflammation, while serum was used for systemic inflammation).

Health status was assessed using the COPD Assessment Test (CAT) questionnaire, validated for Japanese patients and completed prior to lung function testing. The number of participants who experienced COPD exacerbations during the treatment period was measured, and the occurrence of COPD exacerbations was assessed on each day of evaluation in accordance with the defined severity classifications. ${ }^{7}$

\section{Safety}

Adverse events (AEs) and serious AEs (SAEs) were monitored from the start of study treatment through to the follow-up visit.

\section{Statistical methods}

The sample size ( $\mathrm{n}=30$ per group) was based on a previous study of SFC in COPD. ${ }^{11}$ A statistical determination of sample size was used to assess the clinical validity of the interpretation of the study results.

The primary end point (differential neutrophil count in induced sputum) was analyzed based on the change from baseline (week 0) to week 12. The percentage change from baseline in each subject was calculated and ranked. Ranked values were analyzed using the van Elteren extension to the Wilcoxon rank sum test; ${ }^{24}$ smoking status was used as a stratification variable. The other biomarkers in sputum and serum were also assessed using the Wilcoxon rank sum test.

Postbronchodilator $\mathrm{FEV}_{1}$ and $\mathrm{FVC}$ data were analyzed using analysis of covariance, with study center, age, sex, smoking status, and baseline values as covariates. For the CAT score, descriptive statistics were calculated for the observed data at each time point and the change from baseline; the two-sided $95 \%$ confidence interval (CI) of the mean change was estimated.

Analyses were performed on the per-protocol (PP) and intent-to-treat (ITT) populations (Figure 1). The results from the PP population were of primary interest and are presented here; the ITT results supported the PP results and are not presented. Safety data were listed and summarized. Analysis was done primarily using SAS version 9.2 and also version 9.3 software.

\section{Ad hoc analyses}

Bootstrap statistical analysis was performed on the neutrophil and IL-8 data. Bootstrap statistics can supplement nonparametric statistical methods and involves randomly resampling a set of data (with replacement) multiple times (eg, 10,000 times) so that statistical conclusions can be drawn from the data collection. ${ }^{25}$

Responder analysis was based on the definition of "responder" as having a $\geq 20 \%$ decrease in sputum neutrophils ${ }^{26}$ and $\geq 200 \mathrm{pg} / \mathrm{mL}$ decrease in sputum IL-8. ${ }^{27}$ The responder rate was displayed with $95 \%$ CI based on binomial probability.

\section{Results}

\section{Subject demographics and disposition}

Subject demographics and smoking history are summarized in Table 1 . The study population was similar across both treatment groups. In each group, 28 subjects were enrolled, of which 26 per group completed the study (Figure 1). All subjects randomized to treatment received at least one dose of SFC 250.

\section{Efficacy}

\section{Inflammatory biomarkers in sputum and serum}

Some sputum samples were contaminated with high numbers of squamous epithelial cells (SEC). This rendered them unacceptable for inclusion in the analyses. Therefore, the ad hoc analysis of inflammatory biomarkers in sputum are presented for the samples of acceptable quality only ( $\mathrm{n}=19$ for SFC 250; $\mathrm{n}=10$ for placebo). Although this affects the statistical power of the study, it should be noted that the analyses performed including the contaminated sputum samples (ie, planned analysis of the PP population) supported those performed with their exclusion and did not affect the overall outcome.

Summary statistics for each visit (number of subjects and quartiles: $25 \%$ point, median, and $75 \%$ point) showed a numerical decrease in the differential neutrophil counts from baseline to week 12 (Table 2). A greater numerical decrease 


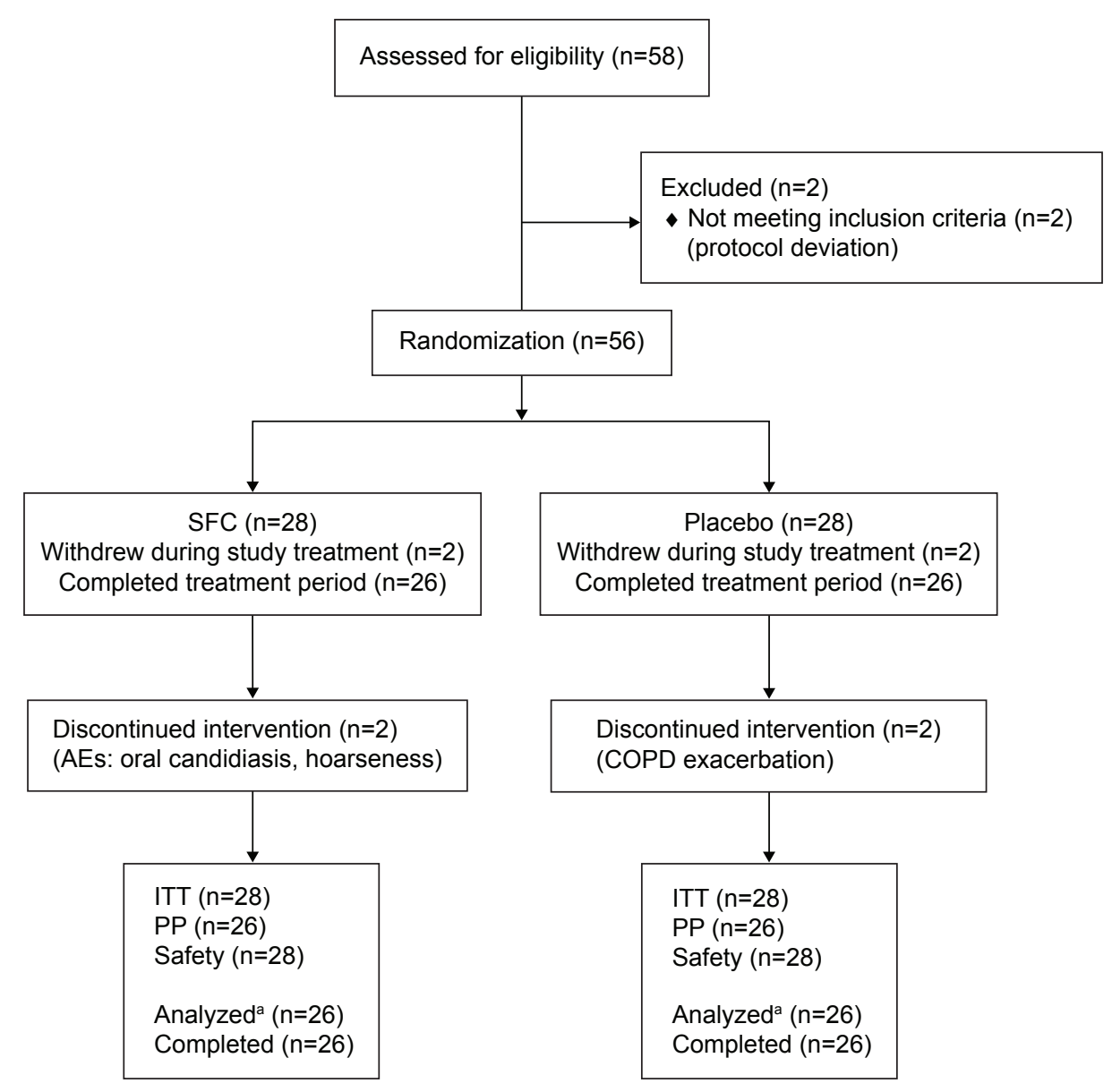

Figure I CONSORT (consolidated standards of reporting trials) flow diagram.

Notes: a'Samples not contaminated with squamous cells. The ITT population comprised all subjects who had evaluable sputum samples at baseline and who received at least a single dose of trial medication. The PP population comprised all subjects in the ITT population who also had an evaluable sputum sample at end point and no major protocol violations. Abbreviations: AE, adverse event; COPD, chronic obstructive pulmonary disease; ITT, intent-to-treat; PP, per-protocol; SFC, salmeterol/fluticasone propionate.

Table I Summary of demographic characteristics (per-protocol population)

\begin{tabular}{|c|c|c|}
\hline & $\begin{array}{l}\text { SFC } 250 \\
N=26\end{array}$ & $\begin{array}{l}\text { Placebo } \\
\mathrm{N}=26\end{array}$ \\
\hline Age (years) & $64.7(9.31)$ & $62.2(8.06)$ \\
\hline \multicolumn{3}{|l|}{ Sex, n (\%) } \\
\hline Male & $25(96 \%)$ & $26(100 \%)$ \\
\hline Female & I (4\%) & 0 \\
\hline Height $(\mathrm{cm})$ & 168.42 & 166.77 \\
\hline Weight (kg) & 66.44 & 64.58 \\
\hline \multicolumn{3}{|c|}{ Concurrent medical conditions n (\%) } \\
\hline Yes & $23(88 \%)$ & $21(81 \%)$ \\
\hline No & $3(12 \%)$ & $5(19 \%)$ \\
\hline Smoking history, $\mathrm{n}(\%)$ & $26(100 \%)$ & $26(100 \%)$ \\
\hline Current smoker, n (\%) & $12(46 \%)$ & 14 (54\%) \\
\hline \multicolumn{3}{|c|}{ Stopped smoking in last 6 months, $\mathrm{n}(\%)$} \\
\hline Yes & $4(29 \%)$ & $3(25 \%)$ \\
\hline No & $10(7 \mid \%)$ & $9(75 \%)$ \\
\hline Number of pack years (years) & $58.96(34.028)$ & $59.92(29.425)$ \\
\hline $\mathrm{FEV}_{\text {, }}(\mathrm{L})$ at baseline & $1.983(0.5797)$ & $2.044(0.4638)$ \\
\hline
\end{tabular}

Notes: $\mathrm{N}$ represents the number of subjects, including those with sputum samples contaminated with squamous cells. Results are expressed as $\mathrm{n}(\%)$, mean, or as mean (SD).

Abbreviations: $F E V$, forced expiratory volume in I second; SD, standard deviation; SFC, salmeterol/fluticasone propionate. in differential neutrophil count $(9.95 \%)$ was observed from baseline following SFC 250 versus placebo. However, this was not significantly different $(P=0.6269)$ (Table 2).

After 12 weeks, SFC 250 also did not produce any statistically significant differences in the change from baseline in sputum or serum biomarker levels compared with placebo (Table 3). For IFN-gamma-positive cells and perforinpositive cells in sputum, and hs-CRP in sputum supernatant, no statistical analysis or summarization was performed, due to insufficient sample volume and quality.

Median percentage change in sputum neutrophils from baseline (estimated by the Bootstrap statistical method) showed a decrease of $27.9 \%(n=19)$ following SFC 250 versus $1.3 \%(\mathrm{n}=10)$ with placebo, and the difference between the two groups was $-26.6 \%$ (95\% CI: $-88.2,37.0)$. In addition, sputum IL-8 showed a decrease of $43.2 \%(n=19)$ with SFC 250 versus an increase of $48.3 \%(n=10)$ with placebo; the difference between the two groups was $-85.0 \%$ (95\% CI: -557.8, 59.9) (Table 4). 
Table 2 Statistical analysis of change from baseline in differential neutrophil count in induced sputum at week 12

\begin{tabular}{lll}
\hline $\begin{array}{l}\text { Sputum differential } \\
\text { neutrophils (\%) }\end{array}$ & SFC 250 & $\begin{array}{l}\text { Placebo } \\
\mathbf{N}=\mathbf{1 9}\end{array}$ \\
\hline Raw median at baseline & 48.50 & 38.25 \\
Raw median at week 12 & 19.00 & 24.50 \\
Raw median change from baseline & -7.90 & -3.00 \\
SFC 250 - placebo & & \\
Median difference & -9.95 & \\
95\% Cl & $-25.000,10.000$ & \\
P-value & 0.6269 & \\
\hline
\end{tabular}

Notes: Samples contaminated with squamous cells, and therefore of low quality, were excluded. $\mathrm{N}$ represents the number of subjects with samples not contaminated with squamous cells.

Abbreviations: $\mathrm{Cl}$, confidence interval; SFC, salmeterol/fluticasone propionate.

The degree of sputum neutrophilia in COPD is associated with the annual rate of decline in lung function. A difference of $20 \%$ in sputum neutrophils was observed between slow and fast $\mathrm{FEV}_{1}$ decline and is considered a clinically relevant change. ${ }^{26}$ In the responder analysis at week $12,42 \%(8 / 19)$ of subjects in the SFC 250 group showed $a \geq 20 \%$ change from baseline in sputum differential neutrophil count as compared with $10 \%(1 / 10)$ of subjects in the placebo group. Similarly, at week $12,47 \%(9 / 19)$ of subjects in the SFC 250 showed a decrease from baseline in IL- 8 , of $\geq 200 \mathrm{pg} / \mathrm{mL}$, compared with $20 \%(2 / 10)$ who showed a decrease following placebo.

\section{Lung function}

In the PP analysis ( $\mathrm{n}=52)$, there was no significant difference between SFC 250 and placebo in the change from baseline

Table 3 Median difference at week 12, between SFC 250 and placebo, in the change from baseline in levels ofbiomarkers in sputum and serum (per-protocol population)

\begin{tabular}{|c|c|c|}
\hline & $\begin{array}{l}\text { Median difference } \\
(95 \% \mathrm{CI})\end{array}$ & $P$-value \\
\hline \multicolumn{3}{|l|}{ Sputum } \\
\hline $\begin{array}{l}\text { Inflammatory cells, total } \\
\text { count (cells } \times 10^{5} / \mathrm{mL} \text { ) }\end{array}$ & $0.380(-1.9700,2.6200)$ & 0.5920 \\
\hline \multicolumn{3}{|l|}{ Sputum supernatant } \\
\hline IL-8 (pg/mL) & $-62.0(-1753.00,582.80)$ & 0.6561 \\
\hline MPO (ng/mL) & $10.70(-94.200,291.600)$ & 0.6207 \\
\hline SP-D (ng/mL) & $10.00(-10.100,41.200)$ & 0.5802 \\
\hline \multicolumn{3}{|l|}{ Serum } \\
\hline IL-6 (pg/mL) & $-0.10(-0.900,0.700)$ & 0.9747 \\
\hline IL-8 (pg/mL) & $0.70(-5.100,3.700)$ & 0.7655 \\
\hline hsCRP (ng/mL) & $-17.5(-336.00,4 \mid 5.00)$ & 0.8718 \\
\hline SP-D (ng/mL) & $0.00(-9.400,10.700)$ & 0.9632 \\
\hline CC-I6 (ng/mL) & $0.00(-0.700,0.200)$ & 0.5798 \\
\hline
\end{tabular}

Notes: Per-protocol population (placebo, $\mathrm{n}=26 ; \mathrm{SFC} 250, \mathrm{n}=26$ ).

Abbreviations: CC-16, Clara cell I6; Cl, confidence interval; hsCRP, high-sensitivity C-reactive protein; IL, interleukin; MPO, myeloperoxidase; SFC, salmeterol/fluticasone propionate; SP-D, surfactant protein-D. in $\operatorname{FEV}_{1}(P=0.5266)$ or FVC $(P=0.7251)$ after 12 weeks (Table 5).

\section{Other}

For the PP analysis set $(\mathrm{n}=52)$, there was no significant difference in CAT scores between SFC 250 and placebo at week 12: the change from baseline in total score $(95 \% \mathrm{CI})$ was $-0.2(-1.84,1.54)$ and $-0.5(-2.30,1.30)$ for SFC 250 and placebo, respectively. Two COPD exacerbations were reported by one subject in the placebo group, and both were reported as SAEs; no COPD exacerbations were reported in the SFC 250 group.

\section{Safety}

In the safety population analysis $(\mathrm{n}=56$ ) during the treatment period, $14(50 \%)$ subjects reported AEs following treatment with SFC 250 compared with 12 (43\%) patients reporting AEs with placebo. Adverse drug reactions (ADRs) were reported in seven (25\%) subjects in the SFC 250 group and no subjects in the placebo group; dysphonia (five [18\%]) and oral candidiasis (two [7\%]) were the most frequently reported. The remaining ADRs were each reported in $4 \%$ of subjects (oropharyngeal discomfort, pharyngitis, and stomatitis). One SAE was reported in the SFC 250 group (diabetes progression) and two in the placebo group (COPD exacerbations); no deaths were reported during the study.

\section{Discussion}

In the primary analysis, repeated dosing of SFC 250 over 12 weeks in Japanese COPD patients did not produce significant changes in sputum inflammatory cells, sputum and serum biomarkers, lung function, or health status compared with placebo. As expected, SFC was well-tolerated in this population, with no COPD exacerbations experienced in the SFC 250 group.

There are a number of possible explanations for the apparent lack of anti-inflammatory effect of SFC 250 in the primary analysis of this study. Due to SEC contamination of sputum samples, the number of acceptable samples for analysis and comparison was decreased. SEC contamination was seen at all three sites, although the degree of contamination varied. SEC contamination can adversely affect the reproducibility of sputum cell differential counts, although the impact of such contamination has not been studied in a controlled manner. ${ }^{28}$ The extent of contamination can vary between subjects and between the different methods of processing samples (whole expectorate versus selected methods). In our study, however, the inclusion or exclusion of contaminated samples did not 
Table 4 Median of \% change from baseline neutrophils and IL-8, in sputum

\begin{tabular}{llllll}
\hline & $\begin{array}{l}\text { Placebo } \\
(\mathbf{N}=10)\end{array}$ & $\begin{array}{l}\text { SFC 250 } \\
(\mathbf{N}=19)\end{array}$ & $\begin{array}{l}\text { Differences } \\
\text { (placebo - SFC 250) }\end{array}$ & $\begin{array}{l}\mathbf{9 5 \%} \mathbf{C l} \\
\text { lower }\end{array}$ & $\begin{array}{l}\mathbf{9 5 \%} \text { Cl } \\
\text { upper }\end{array}$ \\
\hline Neutrophils & -1.3 & -27.9 & -26.6 & -88.2 & 37.0 \\
IL-8 & 48.3 & -43.2 & -85.0 & -557.8 & 59.9 \\
\hline
\end{tabular}

Notes: Bootstrap method $(B=10,000)$. N represents the number of subjects with samples not contaminated with squamous cells.

Abbreviations: $\mathrm{Cl}$, confidence interval; IL-8, interleukin-8; SFC, salmeterol/fluticasone propionate.

affect the overall outcome - the primary and secondary end points were not achieved even when the contaminated samples were included in the analysis.

Studies in COPD have shown that sputum, bronchoalveolar lavage (BAL), and bronchial biopsies represent different lung compartments: ${ }^{29,30}$ sputum mainly originates from the large, central airways; BAL originates from the smaller bronchioles and alveoli; ${ }^{30}$ while biopsy samples can contain cells from the large or smaller airways, depending on the site chosen. ${ }^{19,29}$ Previous studies using SFC 500 used a combination of sputum and biopsy samples to measure anti-inflammatory effects. ${ }^{10,11}$ However, it is difficult to obtain IRB approval for the use of bronchial biopsies for research purposes in Japan, so sputum induction was chosen for our study. Induced sputum provides a practical method that can be used in the clinic and is less invasive for the subject than biopsy. However, the lack of biopsy data meant that we could not compare our sputum data with earlier studies, nor explore the effects in more peripheral airways. Furthermore,

Table 5 Statistical analysis of COPD pulmonary function tests at week 12 (per-protocol population)

\begin{tabular}{|c|c|c|}
\hline & $\begin{array}{l}\text { SFC } 250 \\
N=26\end{array}$ & $\begin{array}{l}\text { Placebo } \\
\mathrm{N}=26\end{array}$ \\
\hline \multicolumn{3}{|l|}{$\mathrm{FEV}_{1}(\mathrm{~L})$} \\
\hline Baseline mean (SE) & $1.983(0.1137)$ & $2.044(0.0910)$ \\
\hline Adjusted change & 0.078 & 0.053 \\
\hline \multicolumn{3}{|l|}{ from baseline } \\
\hline \multicolumn{3}{|l|}{ SFC 250 - placebo } \\
\hline Mean difference $(95 \% \mathrm{Cl})$ & $0.024(-0.0524,0.1009)$ & \\
\hline$P$-value & 0.5266 & \\
\hline \multicolumn{3}{|l|}{ FVC (L) } \\
\hline Baseline mean (SE) & $3.445(0.1532)$ & $3.35 I(0.1102)$ \\
\hline Adjusted change & -0.214 & -0.257 \\
\hline \multicolumn{3}{|l|}{ from baseline } \\
\hline \multicolumn{3}{|l|}{ SFC 250 - placebo } \\
\hline Mean difference $(95 \% \mathrm{Cl})$ & $0.043(-0.2015,0.2873)$ & \\
\hline$P$-value & $0.725 I$ & \\
\hline
\end{tabular}

Notes: $\mathrm{N}$ represents the number of subjects including those with sputum samples contaminated with squamous cells.

Abbreviations: $\mathrm{Cl}$, confidence interval; COPD, chronic obstructive pulmonary disease; $\mathrm{FEV}_{1}$, forced expiratory volume in I second; FVC, forced vital capacity; $\mathrm{SE}$, standard error; SFC, salmeterol/fluticasone propionate. sputum methodology may not always be reproducible, and previous sputum data relating to inflammatory markers in COPD have been controversial. ${ }^{10}$ The conduct of sputum induction across multiple sites may have also caused further variability in the outcomes.

The available SFC 500 data vary with regard to changes in inflammatory markers and lung function. ${ }^{10-12}$ Compared with placebo, SFC 500 had significant anti-inflammatory effects measured in biopsy tissue in COPD patients. ${ }^{10,11}$ However, it did not significantly reduce sputum levels of IL- 8 or total cell counts, ${ }^{10}$ BAL levels of neutrophils or eosinophils, ${ }^{11}$ or serum CRP or IL-6 but did significantly decrease serum SP-D. ${ }^{12}$ In two of the studies, lung function was significantly improved following SFC 500 compared with placebo, ${ }^{10,12}$ while in the third, neither lung function nor health status were significantly improved, ${ }^{11}$ which concurs with our own observations. Stănescu et al showed increased levels of neutrophils in sputum were correlated with a rapid decline in $\mathrm{FEV}_{1}$ over a 15-year follow-up period in smokers and ex-smokers. ${ }^{26}$ The difference in percentage neutrophils between the fast and moderate decliners was $10 \%$, while the difference between fast and slow decliners was $30 \%$, therefore, $20 \%$ may be considered as a clinically relevant change in neutrophils. Our ad hoc responder analysis showed that almost half the subjects (42\%) in the SFC 250 group reached a 20\% threshold for change in differential neutrophil count compared with $10 \%$ in the placebo group, thus providing possible evidence of an anti-inflammatory effect. Similarly, sputum neutrophilia has been associated with increased levels of the chemoattractant IL- $8,{ }^{18}$ and good correlation has been seen between sputum IL-8 and neutrophils. ${ }^{31-33}$ At week 12, $47 \%$ of subjects in the SFC 250 group showed a change from baseline in IL-8 of $\geq 200 \mathrm{pg} / \mathrm{mL}$ compared with $20 \%$ following placebo, which is the threshold for IL-8 stimulation of human neutrophil chemotaxis. Therefore, $200 \mathrm{pg} / \mathrm{mL}$ may be considered a clinically relevant change. ${ }^{27}$

Our study had some limitations, in addition to the use of sputum induction and the effect of SEC contamination, which may have influenced the outcome. We did not control 
for the presence of potential bacterial colonization in the sputum, which may have affected the degree of neutrophilia and IL-8 concentrations. Although neutrophils play an important role in COPD, they may not be the ideal marker of anti-inflammatory effects of treatment. However, sputum neutrophils appear to be a good marker for evaluating COPD inflammation in the airways, although sputum samples can be difficult to collect and process.

A 12-week treatment period was chosen to enable comparison with other studies ${ }^{10,11}$ but is a relatively short duration and may have limited the possibility of showing any change in $\mathrm{FEV}_{1}$ or health status, especially with SFC containing the lower dose of FP (250 mcg). Our study may not have been sufficiently powered to show differences in lung function or health status, and so analysis of these parameters was performed on a preliminary basis. Studies using the rate of decline of $\mathrm{FEV}_{1}$ or reduction of exacerbations as primary end points generally require longer treatment duration as well as larger sample sizes. $^{34}$ In our study, almost $50 \%$ of subjects were current smokers, but our study was not powered to explore the impact of smoking status on the outcomes. However, some data suggest that smoking status of subjects may modify the clinical effects of inhaled corticosteroid, indicating that they appear more effective in former than in current smokers. ${ }^{10,35}$ The final numbers in our study did not permit stratification based on smoking status. Other factors, such as disease history and treatment course, may also have affected the outcome. Despite the limitations, this was the first study of its kind to evaluate the possible anti-inflammatory effects of SFC 250 in a Japanese COPD population. As a result of low subject sample numbers, further ad hoc statistical analysis suggested that SFC 250 may reduce both sputum neutrophils and IL-8 in COPD.

\section{Conclusion}

On the basis of the primary PP analysis, SFC 250 did not produce significant changes from baseline in sputum neutrophil levels or other sputum or serum inflammatory markers compared with placebo, and there also was no corresponding change in lung function or health status. Secondary ad hoc statistical analysis showed that SFC 250 reduced the number of sputum neutrophils after 12 weeks, with almost $50 \%$ of patients showing a clinically relevant decrease of $20 \%$ and a decrease in levels of sputum IL-8 by a clinically relevant $200 \mathrm{pg} / \mathrm{mL}$.

It is important to understand the underlying pathophysiology of COPD, particularly with respect to inflammation, in order to determine the utility of anti-inflammatory treatment and improve pharmacological therapy of COPD in the future. Our study has provided further information on this highly complex disease and the possible impact of treatment with SFC 250 in Japanese COPD patients. Additional work, including larger studies with longer treatment period, are now required.

\section{Acknowledgments}

Funding for this study was provided by GlaxoSmithKline (NCT01607398).

The authors would like to thank the following people for their contributions: Daisuke Yoshimoto and Tomoyuki Hayamizu, Medical Affairs Respiratory, GlaxoSmithKline KK; Gerald Hagan, independent consultant; and the Investigators Katsuji Hashimoto, Director of AMC, Nishi-Umeda Clinic, Department of Internal Medicine; Yasuaki Miki, Physician, Department of Internal Medicine, Nanko Clinic; Yumiko Mizukubo, Naoko Yoshii, and Naoki Ijiri from the Department of Respiratory Medicine, Graduate School of Medicine, Osaka City University, Asahi-machi, Abeno-ku, Osaka, Japan; and Yoshihiro Tochino, Assistant Professor, Department of Medical Education and General Practice, Graduate School of Medicine, Osaka City University who participated in subject recruitment; SRL Medisearch Inc., for performing the biomarker analyses; the Institute of Japanese Union of Scientists and Engineers for performing the statistical analysis; and CIMIC Co, Ltd for performing the data management.

\section{Author contributions}

All authors were involved in the design of the study, acquisition of and analysis of data, and the drafting and critical revision of the manuscript, as well as in approval of the final proof for publishing.

\section{Disclosure}

Akihiro Kobayashi and Yukio Makihara were employees of GlaxoSmithKline at the time of the study conduct, with no other relationships or activities that could appear to have influenced the submitted work. Kazuhisa Asai discloses having received honoraria/consulting fees from GlaxoSmithKline for participating on the advisory board meeting, and his university has received research grants from the commercial entity that sponsored the study. Malcolm Johnson is an independent respiratory consultant employed by GlaxoSmithKline to help in the design and conduct of the study. Malcolm Johnson is a shareholder in Glaxo SmithKline but has no other relationships or activities that could appear to have influenced the submitted work. Medical writing and editorial support, in the form of development of draft outline, development of manuscript (all drafts), assembling 
of tables and the collating of author comments was provided by Dr Kathryn White of Cathean Ltd and was funded by GlaxoSmithKline. The authors report no other conflicts of interest.

\section{References}

1. Japanese Respiratory Society. [Japanese Respiratory Society COPD Guideline ver. 4]. Tokyo, Japan: Tokyo Incorporated Association, JRS; 2013. Japanese.

2. Betsuyaku T, Kato M, Fujimoto K, et al. A study to assess COPD Symptom-based Management and to Optimise treatment Strategy in Japan (COSMOS-J) based on GOLD 2011. Int J Chron Obstruct Pulmon Dis. 2013;8:453-459.

3. Ichinose $\mathrm{M}$, Aizawa $\mathrm{H}$, Ishizaka $\mathrm{A}$, et al. [Chronic obstructive pulmonary disease (COPD) burden in Japan - confronting COPD Japan survey]. Nihon Kokyuki Gakkai Zasshi. 2007;45(12):927-935. Japanese.

4. Nakano Y, Mishima M, Nagai A, Yoshimoto D, et al. [Undiagnosed COPD in Japanese patients, aged over 40 with history of smoking and repeated chest infections, consulting in primary care]. Japan Med Assoc J. 2013;142:1093-1098. Japanese.

5. Fukuchi $Y$, Nishimura $M$, Ichinose $M$, et al. COPD in Japan: the Nippon COPD Epidemiology study. Respirology. 2004;9(4):458-465.

6. Agusti AGN. COPD, a multicomponent disease: implications for management. Respir Med. 2005;99(6):670-682.

7. Global Initiative for Chronic Obstructive Lung Disease. Global Strategy for the Diagnosis, Management, and Prevention of Chronic Obstructive Pulmonary Disease. Global Initiative for Chronic Obstructive Lung Disease. Available from: http://www.goldcopd.com/uploads/users/ files/GOLD_Report_2014_Oct30.pdf. Accessed December 15, 2014.

8. Ferguson GT, Anzueto A, Fei R, Emmett A, Knobil K, Kalberg C. Effect of fluticasone propionate/salmeterol (250/50 microg) or salmeterol (50 microg) on COPD exacerbations. Respir Med. 2008;102(8): 1099-1108.

9. Ichinose M, Mishima M, Mashiko T, Nagai A. [Clinical study to evaluate the effects of changing from salmeterol to salmeterol/fluticasone propionate combination (SFC) in patients with COPD]. Kokyu. 2008; 27(11):1091-1100. Japanese.

10. Barnes NC, Qiu YS, Pavord ID, et al; SCO30005 Study Group. Antiinflammatory effects of salmeterol/fluticasone propionate in chronic obstructive lung disease. Am J Respir Crit Care Med. 2006;173(7):736-743.

11. Bourbeau J, Christodoulopoulos P, Maltais F, Yamauchi Y, Olivenstein R, Hamid Q. Effect of salmeterol/fluticasone propionate on airway inflammation in COPD: a randomised controlled trial. Thorax. 2007;62(11): 938-943.

12. Sin DD, Man SFP, Marciniuk DD, et al; ABC (Advair, Biomarkers in COPD) Investigators. The effects of fluticasone with or without salmeterol on systemic biomarkers of inflammation in chronic obstructive pulmonary disease. Am J Respir Crit Care Med. 2008;177(11):1207-1214.

13. Yawn BP, Raphiou I, Hurley JS, Dalal AA. The role of fluticasone propionate/salmeterol combination therapy in preventing exacerbations of COPD. Int J Chron Obstruct Pulmon Dis. 2010;5:165-178.

14. Hanania NA, Darken P, Horstman D, et al. The efficacy and safety of fluticasone propionate (250 microg)/salmeterol (50 microg) combined in the Diskus inhaler for the treatment of COPD. Chest. 2003;124(3):834-843.

15. Dal Negro RW, Pomari C, Tognella S, Micheletto C. Salmeterol and fluticasone $50 \mathrm{microg} / 250 \mathrm{microg}$ bid in combination provides a better long-term control than salmeterol 50 microg bid alone and placebo in COPD patients already treated with theophylline. Pulm Pharmacol Ther. 2003;16(4):241-246.
16. Anzueto A, Ferguson GT, Feldman G, et al. Effect of fluticasone propionate/salmeterol (250/50) on COPD exacerbations and impact on patient outcomes. COPD. 2009;6(5):320-329.

17. MacNee W. Systemic inflammatory biomarkers and co-morbidities of chronic obstructive pulmonary disease. Ann Med. 2013;45(3): 291-300.

18. Dickens JA, Miller BE, Edwards LD, Silverman EK, Lomas DA, Tal-Singer R; for the Evaluation of COPD Longitudinally to Identify Surrogate Endpoints (ECLIPSE) study Investigators. COPD association and repeatability of blood biomarkers in the ECLIPSE cohort. Respir Res. 2011;12:146.

19. Röpcke S, Holz O, Lauer G, et al. Repeatability of and relationship between potential COPD biomarkers in bronchoalveolar lavage, bronchial biopsies, serum, and induced sputum. PLoS One. 2012;7(10):e46207.

20. Bizeto L, Mazzolini AB, Ribeiro M, Stelmach R, Cukier A, Nunes MP. Interrelationship between serum and sputum inflammatory mediators in chronic obstructive pulmonary disease. Braz J Med Biol Res. 2008; 41(3):193-198.

21. Singh D, Edwards L, Tal-Singer R, Rennard S. Sputum neutrophils as a biomarker in COPD: findings from the ECLIPSE study. Respir Res. 2010;11:77.

22. Paggiaro PL, Chanez P, Holz O, et al. Sputum induction. Eur Respir J Suppl. 2002;37:3s-8s.

23. Vestbo J, Anderson W, Coxson HO, et al; ECLIPSE Investigators. Evaluation of COPD Longitudinally to Identify Predictive Surrogate End-points (ECLIPSE). Eur Respir J. 2008;31(4):869-873.

24. van Elteren PH. On the combination of independent two-sample tests of Wilcoxon. B Int Statist Inst. 1960;37:351-361.

25. Henderson AR. The bootstrap: a technique for data-driven statistics. Using computer-intensive analyses to explore experimental data. Clin Chim Acta. 2005;359(1-2):1-26.

26. Stănescu D, Sanna A, Veriter C, et al. Airways obstruction, chronic expectoration, and rapid decline of $\mathrm{FEV}_{1}$ in smokers are associated with increased levels of sputum neutrophils. Thorax. 1996;51(3):267-271.

27. Lin F, Nguyen CM, Wang SJ, Saadi W, Gross SP, Jeon NL. Effective neutrophil chemotaxis is strongly influenced by mean IL-8 concentration. Biochem Biophys Res Commun. 2004;319(2):576-581.

28. Sohani ZN, Strinich TX, Watson B, et al. Reproducibility of sputum differential cell counts is not affected by squamous epithelial cells. J Asthma. 2011;48(9):952-956.

29. Tsoumakidou M, Tzanakis N, Siafakas NM. Induced sputum in the investigation of airway inflammation of COPD. Respir Med. 2003;97(8):863-871.

30. Jen R, Rennard SI, Sin DD. Effects of inhaled corticosteroids on airway inflammation in chronic obstructive pulmonary disease: a systematic review and meta-analysis. Int J Chron Obstruct Pulmon Dis. 2012;7:587-595.

31. Malerba M, Ricciardolo F, Radaeli A, et al. Neutrophilic inflammation and IL-8 levels in induced sputum of alpha-1-antitrypsin PiMZ subjects. Thorax. 2006;61(2):129-133.

32. Kulkarni N, Cooke MS, Grigg J. Neutrophils in induced sputum from healthy children: role of interleukin-8 and oxidative stress. Respir Med. 2007;101(10):2108-2112.

33. Ishikawa N, Hattori N, Kohno N, Kobayashi A, Hayamizu T, Johnson M. Airway inflammation in Japanese COPD patients compared with smoking and nonsmoking controls. Int J Chron Obstruct Pulmon Dis. 2015;10:185-192.

34. Barnes N. Reducing inflammation in COPD: the evidence builds. Thorax. 2007;62(11):927-928.

35. Lazarus SC, Chinchilli VM, Rollings NJ, et al; National Heart Lung and Blood Institute's Asthma Clinical Research Network. Smoking affects response to inhaled corticosteroids or leukotriene receptor antagonists in asthma. Am J Respir Crit Care Med. 2007;175(8):783-790. 
International Journal of COPD

\section{Publish your work in this journal}

The International Journal of COPD is an international, peer-reviewed journal of therapeutics and pharmacology focusing on concise rapid reporting of clinical studies and reviews in COPD. Special focus is given to the pathophysiological processes underlying the disease, intervention programs, patient focused education, and self management protocols.

This journal is indexed on PubMed Central, MedLine and CAS. The manuscript management system is completely online and includes a very quick and fair peer-review system, which is all easy to use. Visit http://www.dovepress.com/testimonials.php to read real quotes from published authors 